\title{
Ensaios clínicos são mais difíceis de serem conduzidos em COVID-19 do que em outras condições?
}

\section{Rafael Leite Pacheco ${ }^{1}$ (i) Ana Luiza Cabrera Martimbianco ${ }^{2}$ (1) Raphael Einsfeld Simões Ferreira ${ }^{3}$ (1) Rachel Riera ${ }^{4}$}

`Autor para correspondência. Universidade Federal de São Paulo (São Paulo); Centro Universitário São Camilo (São Paulo). São Paulo, Brasil. rleitepacheco@hotmail.com ${ }^{2}$ Centro Universitário São Camilo (São Paulo); Universidade Metropolitana de Santos (Santos). São Paulo, Brasil. analuizacabrera@hotmail.com ${ }^{3}$ Centro Universitário São Camilo (São Paulo). São Paulo, Brasil. raphael.einsfeld@saocamilo-sp.br ${ }^{4}$ Universidade Federal de São Paulo (São Paulo); Núcleo de Avaliação de Tecnologias em Saúde, Hospital Sírio-Libanês (São Paulo). rachelriera@hotmail.com

PALAVRAS-CHAVE: Ensaios clínicos randomizados. Pesquisa clínica. COVID-19.

A utilização de estudos com delineamentos inadequados e/ou baixo rigor metodológico para dar suporte à tomada de decisão durante o manejo de pacientes com covid-19 está sendo baseada, por alguns, no argumento de que "fazer um ensaio clínico randomizado durante a pandemia é muito mais difícil e demorado". De fato, este argumento vem sendo reproduzido ou adaptado durante debates e publicações, o que parece incoerente com o grande número de estudos sendo conduzidos.

Até a presente data, milhares de ensaios clínicos avaliando intervenções para o tratamento e a profilaxia de covid-19 já foram registrados. A hidroxicloroquina/cloroquina, por exemplo, está sendo avaliada especificamente em mais de cem ensaios clínicos ${ }^{1}$.

A estrutura adotada pela maior parte dos ensaios clínicos sobre covid-19 faz com que sua duração seja similar à de estudos observacionais prospectivos.
Embora a condução de ensaios clínicos seja realmente complexa em qualquer cenário, vários aspectos desta condução têm sido facilitados frente à mobilização de enfrentamento da pandemia.

A seguir serão abordados alguns destes aspectos.

\section{Financiamento}

O financiamento é um dos principais desafios relacionados ao planejamento e à condução de ensaios clínicos. O orçamento necessário pode ser elevado e, em muitos casos, limita a execução de projetos com muitos participantes ou com longo tempo de seguimento.

Devido ao caráter emergencial da pandemia, as instituições privadas e públicas têm destinado fundos específicos para pesquisas voltadas ao covid-19. No Brasil, por exemplo, foram divulgadas chamadas públicas para financiamento de projetos pelo Conselho Nacional de Desenvolvimento Cientifico e Tecnológico (CNPq)², Coordenação de Aperfeiçoamento de Pessoal de Nível Superior 
(CAPES) $)^{3}$ e Fundação de Amparo à Pesquisa do Estado de São Paulo (FAPESP)4. Além disso, bolsas específicas foram disponibilizadas 5 e centenas de pesquisadores mudaram o foco de sua pesquisa para temas relacionados à pandemia ${ }^{6}$. A mobilização e o financiamento emergencial também ocorreram em universidades em outros países ${ }^{\underline{Z}, \underline{8}}$.

\section{Comitês de ética}

A avaliação dos projetos por comitês de ética em pesquisa é aspecto essencial em estudos experimentais em humanos, e que pode estar associado a um aumento do tempo de execução de um ensaio clínico. Em resposta especial à pandemia, a Comissão Nacional de Ética em Pesquisa (CONEP) está considerando os projetos relacionados a covid-19 como tramitação prioritária, o que tem sido adotado por comitês de éticas locais?

\section{Registro de protocolo}

Bases de registros de ensaios clínicos estão atuando em regime de fast-track para pesquisas clínicas relacionados à pandemia. O Registro Brasileiro de Ensaios Clínicos (ReBEC) por exemplo, anunciou a redução dos trâmites para até 48 horas $^{10}$. Bases internacionais de relevância também têm seguido processos similares, como a disponibilização separada de registros de covid-19 em diretórios específicos, visando a otimização do processo de submissão e acesso aos protocolos.

\section{Recrutamento}

Outro ponto-chave no cronograma dos ensaios clínicos é o recrutamento de participantes. Em doenças mais raras, o recrutamento pode levar anos até que seja alcançado o tamanho amostral planejado. Em um cenário de pandemia há grande número de casos, o que pode reduzir o tempo de recrutamento de participantes para o ensaio clínico. Como exemplo, o RECOVERY trial, conduzido por pesquisadores da Universidade de Oxford, já recrutou mais de 11 mil participantes, em pouco mais de dois meses, para avaliar seis potenciais tratamentos para covid-19?

\section{Colaborações nacionais e internacionais}

Alguns ensaios clínicos necessitam de um grande número de participantes para alcançar um poder amostral adequado e a participação de vários centros de recrutamento e administração das intervenções é necessária para que ele se torne exequível. Acordos colaborativos entres diferentes centros incluem aspectos éticos, jurídicos e de padronização que acabam por prolongar o período de planejamento e execução de um ensaio clínico. A atual pandemia tem estimulado com que colaborações nacionais e internacionais sejam consolidadas de modo mais ágil, com menos burocracia e o uso de meio virtuais ${ }^{11}$.

\section{Execução}

Talvez o ponto de maior dificuldade para a condução de ensaios clínicos na pandemia seja a fase de execução. Os centros que conduzem ensaios clínicos geralmente têm grande demanda de atividades assistenciais. Estudos envolvendo pacientes graves ou hospitalizados em unidades de terapia intensiva podem ser mais complexos. No cenário atual, a interação da equipe do estudo com os participantes é dificultada pelo caráter infeccioso da covid-19, o que impacta a coleta de dados e amostras, tanto no ambiente hospitalar quanto no ambulatorial ou no comunitário.

De modo geral, ensaios clínicos que têm sido conduzidos até o momento possuem estrutura simples. A maior parte das intervenções avaliadas é de natureza farmacológica (poucas são mistas ou complexas, o que facilita o mascaramento dos estudos). Dificuldades de randomização e alocação dos pacientes podem ser facilmente resolvidas por um sistema de alocação central utilizando softwares gratuitos.

Alguns dos desfechos primários mais utilizados são comuns de serem coletados e não necessitam de equipe especializada. Os principais exemplos são mortalidade, necessidade de intubação, tempo de hospitalização e resultado de carga viral. Estes desfechos já são rotineiramente coletados e preenchidos em prontuários, o que adiciona pouco esforço na condução de tais ensaios clínicos. 


\section{Publicação}

De maneira similar às plataformas de registro de protocolos, periódicos científicos têm adotado regime de fast-track exclusivo para artigos relacionados à pandemia, o que tem reduzido consideravelmente o tempo de revisão editorial. Adicionalmente, repositórios de estudos em formato pre-print, que até então eram pouco conhecidos, se transformaram em um fonte de informação rotineira e que disponibiliza de modo quase imediato os resultados de um estudo logo após o seu término. Considerações têm sido levantadas sobre este processo, mas não serão abordadas neste texto.

\section{Conclusão}

Embora a execução de ensaios clínicos seja complexa em qualquer cenário, há argumentos que apoiam a hipótese de que sua condução seja facilitada, e não dificultada, sob um cenário de pandemia. A alegação de que não há tempo suficiente ou condições que viabilizem a condução de bons ensaios clínicos precisa, no mínimo, ser argumentada. Para além das considerações metodológicas, a frágil retórica de que estudos observacionais podem ser considerados em detrimento aos ensaios clínicos como fonte de evidências confiáveis sobre efeitos de intervenções não se sustenta.

\section{Contribuição dos autores}

Pacheco RL, Riera R conceberam a ideia do manuscrito. Todos os autores redigiram e aprovaram a versão final.

\section{Conflitos de interesses}

Nenhum conflito financeiro, legal ou político envolvendo terceiros (governo, empresas e fundações privadas, etc.) foi declarado para nenhum aspecto do trabalho submetido (incluindo, mas não se limitando a subvenções e financiamentos, participação em conselho consultivo, desenho de estudo, preparação de manuscrito, análise estatística, etc.).

\section{Referências}

1. DeVito NJ, Liu M, Aronson JK. COVID-19 Clinical Trials Report Card: Chloroquine and Hydroxychloroquine. [Internet]. 2020. [acesso em 2020 jun. 02]. Disponível em: https://www.cebm.net/ covid-19/covid-19-clinical-trials-report-card-chloroquine-andhydroxychloroquine/

2. CNPq. Ministério Da Ciência, Tecnologia, Inovações e Comunicações. Chamada MCTIC/CNPq/FNDCT/MS/SCTIE/Decit Nº 07/2020 Pesquisas para enfrentamento da COVID-19, suas consequências e outras síndromes respiratórias agudas graves. [Internet]. 2020. [acesso em 2020 jun. 01]. Disponível em: http://www.cnpq.br/ web/guest/chamadas-publicas?p_p_id=resultadosportlet_WAR_resultadoscnpqportlet_INSTANCE_OZaM\&filtro=encerradas\&detaIha=chamadaDivulgada\&idDivulgacao $=9382$

3. Fundação CAPES. CAPES - Epidemias - Edital n00/2020. [Internet]. 2020. [acessado em 2020 jun. 01]. Disponível em: https://www.capes. gov.br/bolsas/programas-estrategicos/programas-emergenciais/ programa-de-combate-as-epidemias/prevencao-e-combate-a-surtos-endemias-epidemias-e-pandemias-edital-n-09-2020 4. Fundação de Amparo à Pesquisa do Estado da Bahia. FAPESP
participa de chamada emergencial da UE sobre coronavírus.
[Internet]. 2020. [acesso em 2020 jun. 01]. Disponível em: http://
www.fapesp.br/14103

5. Fundação CAPES. Mais 850 bolsas para combate ao coronavírus. [Internet]. 2020. [acesso em 2020 jun. 01]. Disponível em: https://www.capes.gov.br/mais-850-bolsas-para-combate-aocoronavirus

6. Fundação de Amparo à Pesquisa do Estado da Bahia. Comunicados, chamadas e informações da FAPESP sobre a COVID-19. [Internet]. 2020. [acesso em 2020 jun. 01]. Disponível em: http://www.fapesp.br/covid19

7. University of Oxford. Coronavirus Researchers at Oxford. [Internet]. 2020. [acesso em 2020 jun. 01]. Disponível em: https://www.research.ox.ac.uk/Article/2020-03-18-coronavirusresearchers-at-oxford

8. Grants \& Funding. Coronavirus Disease 2019 (COVID-19): Information for NIH Applicants and Recipients of NIH Funding. [Internet]. 2020. [acesso em 2020 jun. 01]. Disponível em: https:// grants.nih.gov/policy/natural-disasters/corona-virus.htm

9. Conselho Nacional de Saúde. Fluxograma da tramitação ética dos protocolos de pesquisa relacionados à COVID-19 (SARSCOV-2) na comissão nacional de ética em pesquisa. [Internet]. 2020. [acesso em 2020 jun. 01]. Disponível em: http://conselho. saude.gov.br/comissoes-cns/conep/

10. Recovery trial. This national clinical trial aims to identify treatments that may be beneficial for people hospitalised with suspected or confirmed COVID-19. [Internet]. 2020. [acesso em 2020 jun. 01]. Disponível em: https://www.recoverytrial.net/

11. World Health Organization. "Solidarity" clinical trial for COVID-19 treatments. [Internet]. 2020. [acesso em 2020 jun. 01]. Disponível em: https://www.who.int/emergencies/diseases/novelcoronavirus-2019/global-research-on-novel-coronavirus-2019ncov/solidarity-clinical-trial-for-covid-19-treatments 